\section{Hypoxia-selective macroautophagy and cell survival signaled by autocrine PDGFR activity}

\author{
Simon Wilkinson, Jim O'Prey, Michael Fricker, \\ and Kevin M. Ryan ${ }^{1}$
}

Tumour Cell Death Laboratory, Beatson Institute for Cancer Research, Glasgow G61 1BD, United Kingdom

The selective regulation of macroautophagy remains poorly defined. Here we report that PDGFR signaling is an essential selective promoter of hypoxia-induced macroautophagy. Hypoxia-induced macroautophagy in tumor cells is also HIF1 $\alpha$-dependent, with HIF1 $\alpha$ integrating signals from PDGFRs and oxygen tension. Inhibition of PDGFR signaling reduces HIF1 $\alpha$ half-life, despite buffering of steady-state protein levels by a compensatory increase in HIF1a mRNA. This markedly changes HIF1 $\alpha$ protein pool dynamics, and consequently reduces the HIF1 $\alpha$ transcriptome. As autocrine growth factor signaling is a hallmark of many cancers, cellautonomous enhancement of HIF1 $\alpha$-mediated macroautophagy may represent a mechanism for augmenting tumor cell survival under hypoxic conditions.

Supplemental material is available at http://www.genesdev.org.

Received January 9, 2009; revised version accepted April 14, 2009.

During macroautophagy, autophagosomal vesicles (autophagosomes) transport organelles or proteins from the cytosol to the lysosome (Xie and Klionsky 2007). Cellular signals promote the formation of autophagosomes and determine which cytosolic cargoes are sequestered. Macroautophagy has a homeostatic role in general clearing of damaged organelles and proteins in most tissues (Mizushima et al. 2004; Hara et al. 2006; Komatsu et al. 2006). However, in certain situations, cellular stresses induce macroautophagy as an adaptive reponse for the maintenance of cell viability. For example, mitophagy, the specific autophagic degradation of mitochondria, can limit apoptosis in response to cytotoxic agents (Xue et al. 2001; Colell et al. 2007) or down-regulate oxidative phosphorylation as part of the adaptation of primary cells to hypoxia (Zhang et al. 2008). When cells are under conditions of metabolic stress, such as when extracellular nutrients are low, general macroautophagy may be induced to break down cellular proteins into catabolic and anabolic precurors, relieving energy demand and assisting cell survival (Kuma et al. 2004; Scott et al. 2004; Lum et al. 2005; Jin et al. 2007); in the absence of macro-

[Keywords: Autophagy; cell death; hypoxia; cancer] ${ }^{1}$ Corresponding author.

E-MAIL k.ryan@beatson.gla.ac.uk; FAX 44-141-942-6521.

Article is online at http://www.genesdev.org/cgi/doi/10.1101/gad.521709. autophagy, depletion of energy levels and necrosis or apoptosis occurs (Boya et al. 2005; Jin et al. 2007). Although macroautophagy appears to operate broadly as a survival mechanism in cells, there is also mounting evidence that in specific circumstances elevated macroautophagy may be an integral component of cell death programs, although the mechanistic basis for the prodeath role of macroautophagy is unknown (Shimizu et al. 2004; Yu et al. 2004; Feng et al. 2005; Crighton et al. 2006).

\section{Results and Discussion}

Tumor cells encounter hypoxic conditions and become metabolically stressed within poorly vascularized regions of tumors in vivo (Degenhardt et al. 2006). Indeed, macroautophagy colocalizes with hypoxia and promotes cell survival in these regions of tumors (Degenhardt et al. 2006). In a human tumor cell line model, BE colorectal carcinoma, stably expressing GFP-LC3, we found that hypoxia induces macroautophagy, as assessed by accumulation of GFP-LC3 puncta, a marker for autophagosomes (Fig. 1A; Kabeya et al. 2000). Using siRNA oligonucleotides targeting the macroautophagy gene ATG5 (Crighton et al. 2006), we abrogated the autophagic response (Fig. 1B-D) and observed both a decrease in cell viability under hypoxic conditions (Fig. 1E) and a decrease in long-term viability and regrowth potential when cells were replated for outgrowth in a clonogenic survival assay post-treatment (Fig. 1F). These data show that hypoxia-induced macroautophagy is an adaptive mechanism that maintains tumor cell viability in hypoxic environments.

In order to identify signaling mechanisms controlling hypoxia-induced macroautophagy in tumor cells, we performed an RNAi screen across the protein kinome in Drosophila S2R ${ }^{+}$GFP-LC3 reporter cells (cell line described in Supplemental Fig. 1A,B) in order to obtain candidate kinase regulators. We identified the receptor tyrosine kinase $P V r$ as necessary for accumulation of GFPLC3 puncta in response to hypoxia (Supplemental Fig. 1C). There are eight sequence orthologs of $P_{V r}$ in human cells: the VEGFR family kinases $K d r$, Flt4, and Flt1, and the PDGFR family kinases PDGFR $\alpha$, PDGFR $\beta$, Flt3, FMS, and Kit (Supplemental Fig. 2A). We next sought to determine if autocrine signaling through any of these might promote hypoxia-induced macroautophagy in tumor cells.

We tested small-molecule inhibitors of VEGFR and PDGFR family member kinase activity. With VEGFR inhibitors we found no effect (data not shown), but with an inhibitor targeting the PDGFR family (PDGFR-I), we observed dimunition of the accumulation of GFP-LC3 puncta in BE cells in response to hypoxia (Fig. 2A). This effect was specific to hypoxia, as the effect of glucose or amino acid starvation in inducing accumulation of GFPLC3 puncta was unperturbed (Fig. 2A). The endogenous LC3-II to LC3-I ratio, another marker of autophagosome accumulation, was also increased by hypoxia, but was diminished by PDGFR-I, further confirming the conclusions from the puncta analysis (Fig. 2B). These experiments were performed under serum-free conditions. Nevertheless, activity of PDGFR $\beta$, the main documented 


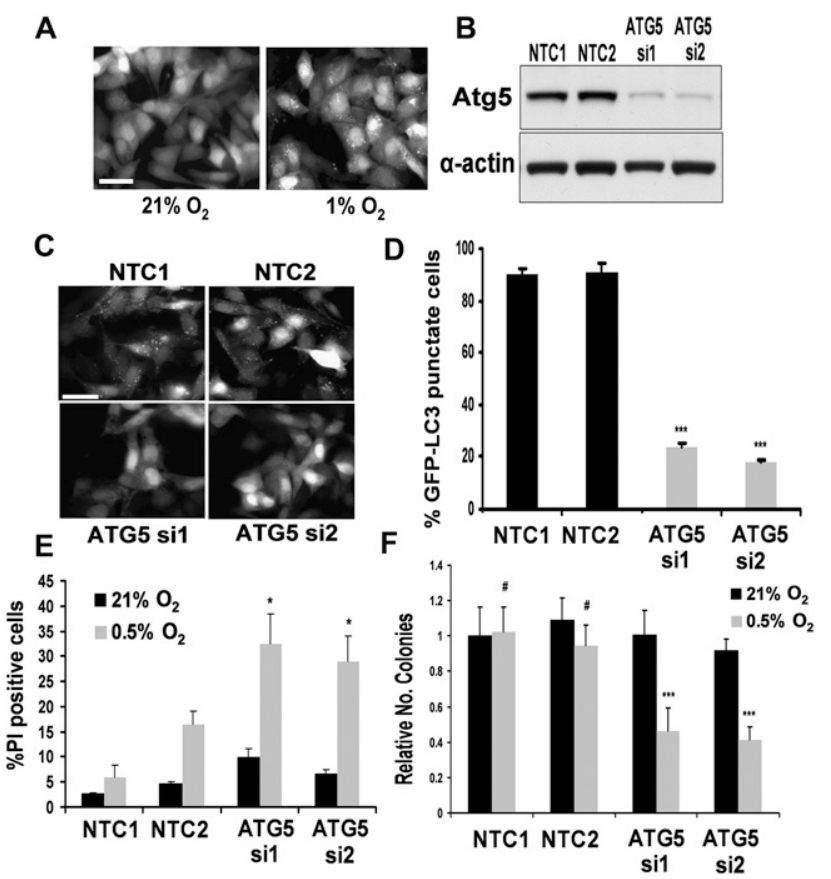

Figure 1. Hypoxia-induced autophagy promotes cell viability in tumor cells. BE GFP-LC3 cells $\left(3 \times 10^{5}\right)$ were plated overnight in sixwell dishes and cultured for $8 \mathrm{~h}$ in normoxic conditions $\left(21 \% \mathrm{O}_{2}\right)$ or hypoxic conditions $\left(1 \% \mathrm{O}_{2}\right)$, and then fixed for fluorescence microscopic imaging of GFP-LC3 (bar, $50 \mu \mathrm{m})(A)$; or transfected with siRNA oligonucleotides NTC1, NTC2, ATG5 si1, or ATG5 si2 $(B-F)$. Forty-eight hours later, cells were immunoblotted for indicated proteins $(B)$ or kept in normoxic conditions $\left(21 \% \mathrm{O}_{2}\right)$ or exposed to hypoxic conditions $\left(0.5 \% \mathrm{O}_{2}\right)(C-F)$, and $24 \mathrm{~h}$ later were fixed for imaging of GFP-LC3 by fluorescence microscopy $(C, D)(C$ contains representative images [bar, $25 \mu \mathrm{m}] ; D$ shows analysis of number of cells containing GFP-LC3 puncta $\left[n=3 \pm\right.$ SEM$_{;}\left\{^{\star \star \star}\right\} P<0.005$ vs. either NTC]) or $96 \mathrm{~h}$ later harvested and stained with propidium iodide for flow cytometric analysis of dead cell number $(n=3 \pm$ SEM; $\left.{ }^{\star}\right] P<0.05$ vs. either NTC) $(E)$ or replated for assessment of colony formation potential upon re-exposure to normoxic conditions $\left(n=6 \pm \mathrm{SD}_{;}[\#]\right.$ not significant; $\left[{ }^{\star \star \star}\right] P<0.005$, vs. cells not exposed to hypoxic stress) $(F)$.

target of PDGFR-I that is expressed in BE cells (Supplemental Fig. 2B), was constitutively observed in both normoxic and hypoxic conditions and, as expected, this was abrogated by inhibitor treatment (Fig. 2C). These data suggested a constitutive autocrine signaling loop through PDGFR $\beta$ that is permissive for hypoxia-induced macroautophagy. Confirming this, inhibition of $P D G F R \beta$ by siRNA transfection also reduced the number of GFPLC3 puncta seen under hypoxic conditions (Fig. 2D). Of the other PDGFR family members, FMS was also detectable in the cells, albeit in our hands only by semiquantitative PCR (Supplemental Fig. 2B), not at the protein level. Although not documented previously, we observed that PDGFR-I could inhibit FMS kinase activity, at least in vitro (Supplemental Fig. 2C). We therefore tested whether FMS inhibition by RNAi also reduced autophagy under hypoxic conditions, and found that this was the case (Fig. 2E). PDGFR-II, a second, chemically unrelated inhibitor of PDGFR $\beta$, and FMS (Supplemental Fig. 2C) also decreased autophagosome levels (Supplemental Fig. 2D). RNAi against Flt1 and $K d r$, the two VEGFR family isoforms we could detect expression of in this cell line, did not inhibit autophagy (Supplemental Fig. 2E-G). Taken together, these data show that autocrine PDGFR $\beta$ and FMS signaling permits hypoxia-induced macroautophagy in a tumor cell line. Consistent with this, we observed that these cells secrete the PDGFR $\beta$ and FMS ligands PDGF and CSF-1 (Supplemental Fig. 2H) and that addition of exogenous PDGF can modestly promote hypoxia-induced autophagy (Supplemental Fig. 2I).

Further measures of hypoxia-induced autophagy in BE cells demonstrated that, in contrast to the effect of hypoxia-induced macroautophagy in mouse embryonic fibroblasts (MEFs) (Zhang et al. 2008), mitochondria (as assessed by COX-IV levels) were not targeted for degra-
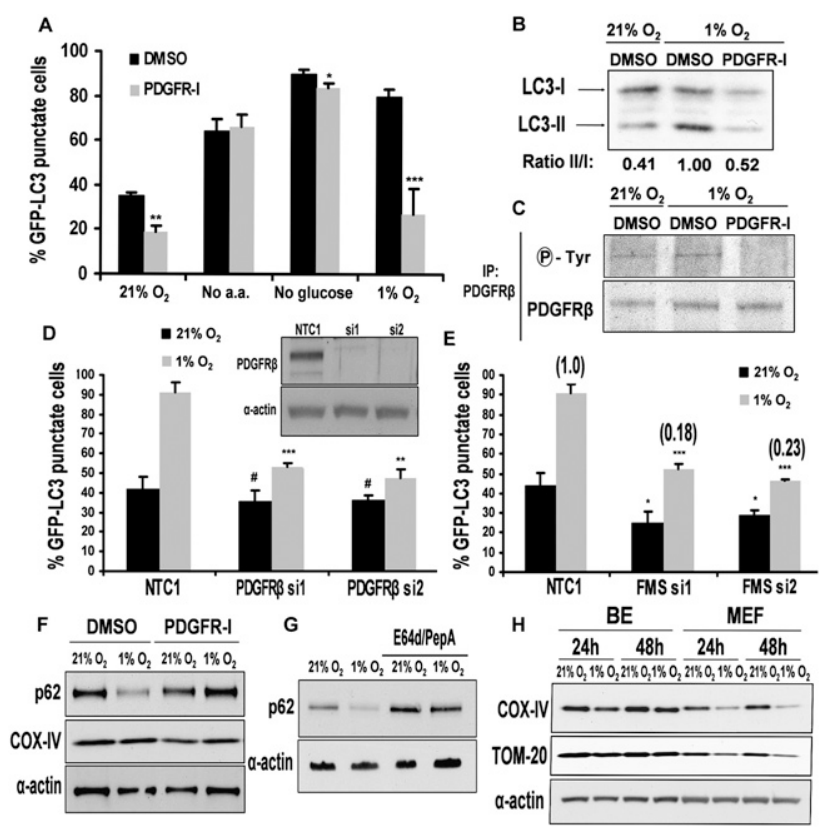

Figure 2. PDGFR family signaling promotes hypoxia-induced autophagy of cytosolic protein. (A) BE GFP-LC3 cells at confluence were cultured in serum-free medium (SFM) $\left(21 \% \mathrm{O}_{2}\right)$ or EBSS (no amino acids [no a.a.]) or glucose-free medium (no glucose), all at $21 \%$ $\mathrm{O}_{2}$, or in SFM at $1 \% \mathrm{O}_{2}\left(1 \% \mathrm{O}_{2}\right)$, plus DMSO vehicle or PDGFR-I (5 $\mu \mathrm{M}$ ) for $8 \mathrm{~h}$, whereupon cells were fixed and analyzed for GFP-LC3 puncta by fluorescence microscopy $\left(n=3 \pm \mathrm{SEM}\left[{ }^{\star}\right] P<0.05 ;{ }^{*}{ }^{\star *}\right]$ $P<0.01 ;{ }^{\left[{ }^{\star \star}\right]} P<0.005$ vs. DMSO control). (B) Parental BE cells (no GFP-LC3 transgene) were cultured in SFM under normoxia $\left(21 \% \mathrm{O}_{2}\right)$ or hypoxia $\left(1 \% \mathrm{O}_{2}\right)$ plus DMSO or PDGFR-I $(5 \mu \mathrm{M})$ for $4 \mathrm{~h}$ and then lysed and immunoblotted for LC3 isoform quantification. (C) BE GFP-LC3 cells at confluence were cultured in SFM under normoxia $\left(21 \% \mathrm{O}_{2}\right)$ or hypoxia $\left(1 \% \mathrm{O}_{2}\right)$ plus DMSO or PDGFR-I $(5 \mu \mathrm{M})$ for $4 \mathrm{~h}$ and then lysed and immunoprecipitated for PDGFR $\beta$ and probed for phospho-tyrosine and PDGFR $\beta$. $(D, E)$ BE GFP-LC3 cells were transfected with indicated siRNA oligonucleotides (nontargeting control [NTC1], or PDGFR $\beta$ or FMS targeting) and at $36 \mathrm{~h}$ post-transfection cultured in SFM under normoxia $\left(21 \% \mathrm{O}_{2}\right)$ or hypoxia $\left(1 \% \mathrm{O}_{2}\right)$ overnight before scoring of the number of GFP-LC3 puncta-positive cells $\left(n=3 \pm \mathrm{SEM}_{;}\left[{ }^{\star \star}\right] P<0.01 ;\left[^{\star \star \star}\right] P<0.005 ;[\#]\right.$ not significant vs. NTC1). Silencing of targets was confirmed by immunoblotting $(D$, inset) or qPCR $(E)$ (numbers in parentheses indicate relative mRNA levels). $(F, G)$ BE GFP-LC3 cells at confluence were cultured in SFM under normoxia $\left(21 \% \mathrm{O}_{2}\right)$ or hypoxia $\left(1 \% \mathrm{O}_{2}\right)$ plus DMSO, PDGFR-I $(5 \mu \mathrm{M})(F)$ or E64d $(10 \mu \mathrm{g} / \mathrm{mL})$ plus pepstatin A $(10 \mu \mathrm{g} / \mathrm{mL})(G)$ for $8 \mathrm{~h}$ $(F)$ or $24 \mathrm{~h}(G)$, and then lysed and immunoblotted for indicated proteins. $(H)$ BE GFP-LC3 cells and primary MEFs at confluence were cultured in SFM under normoxia $\left(21 \% \mathrm{O}_{2}\right)$ or hypoxia $\left(1 \% \mathrm{O}_{2}\right)$ for indicated times and lysed and immunoblotted for indicated proteins. See Supplemental Figure 2J for quantification. 
dation, while the cytosolic macroautophagy target protein p62 was degraded. We observed specific down-regulation of p62, dependent on PDGFR signaling (Fig. 2F), via a lysosomal degradation pathway inhibitable by the protease inhibitors E64d and pepstatin A (Fig. 2G). In MEFs, hypoxia-induced mitophagy is required to down-regulate oxidative phosphorylation to prevent reactive oxygen species accumulation (Zhang et al. 2008). Indeed, analysis of longer time courses of hypoxia demonstrate a markedly greater down-regulation of mitochondrial antigens (COXIV and TOM-20) in primary MEFs as compared with BE tumor cells (Fig. 2H; quantification in Supplemental Fig. 2J). In these tumor cells and other tumor cell lines we found to exhibit PDGFR-dependent hypoxia-induced macroautophagy (Supplemental Fig. $2 \mathrm{~K}$ ), the prosurvival role of macroautophagy in response to hypoxic stress thus may not be related to mitochondrial down-regulation but to cytosolic protein degradation instead. Analysis of canonical signaling pathways downstream from PDGFR family members in BE cells demonstrated that these were unperturbed by PDGFR-I, suggesting that PDGFR is signaling to hypoxia-induced autophagy through a noncanonical mechanism (Supplemental Fig. 2L).

Signaling responses to hypoxia fall into two main categories: HIF-dependent and HIF-independent (Pouyssegur et al. 2006). HIF $1 \alpha$ and HIF $2 \alpha$ are transcription factor subunits, the stability of which increase with lower oxygen, allowing their accumulation and dimerization with HIF1ß/ARNT to form a functional transcription factor (Pouyssegur et al. 2006). Reprogramming of cellular metabolism by HIF1 $\alpha$ up-regulated genes, such as the increase in anaerobic glycolysis by glycolytic enzymes and lactate dehydrogenase, is important for cellular fitness under hypoxia (Pouyssegur et al. 2006). We observed that HIF1 $\alpha$ was stabilized specifically by hypoxia in contrast to other macroautophagy-inducing stimuli (Supplemetnal Fig. 3A). RNAi against ARNT resulted in effective silencing (Fig. 3A) and inhibited hypoxiainduced autophagosome accumulation (Fig. 3B). This demonstrated a transcriptionally mediated macroautophagic response to hypoxia. Further RNAi experiments showed that macroautophagy required, specifically, HIF $1 \alpha$ activity (Fig. 3C,D). It is also evident that the low levels of signaling through the hypoxia response pathway under normoxia are sufficient to sponsor some HIF $1 \alpha$ accumulation (Supplemental Fig. 3A) and autophagy induction (Supplemental Fig. 3B) in these cells, consistent with the observation of a modest inhibition of normoxic autophagy by inhibition of PDGFR family members (Fig. 2A,D,E). BNIP3 and BNIP3L are HIF1 $\alpha$ target genes that have been shown to mediate macroautophagy under hypoxia in MEFs or during erythrocyte maturation in vivo, respectively (Tracy et al. 2007; Sandoval et al. 2008; Zhang et al. 2008). Where this macroautophagy has been characterized, it has be shown to be mitophagic in nature (Sandoval et al. 2008; Zhang et al. 2008). BNIP3 and BNIP3L are regulated in response to hypoxia-mediated HIF1 $\alpha$ activation in BE cells; ARNT siRNA transfection greatly reduced the expression levels of both genes. However, direct BNIP3 and/or BNIP3L silencing did not inhibit hypoxia-induced macroautophagy (Fig. 3E,F). Taken together, these data suggest that the hypoxia-mediated macroautophagy seen in tumor cells is dependent on HIF $1 \alpha$ activity. However, the PDGFRmediated hypoxic macroautophagy here is independent

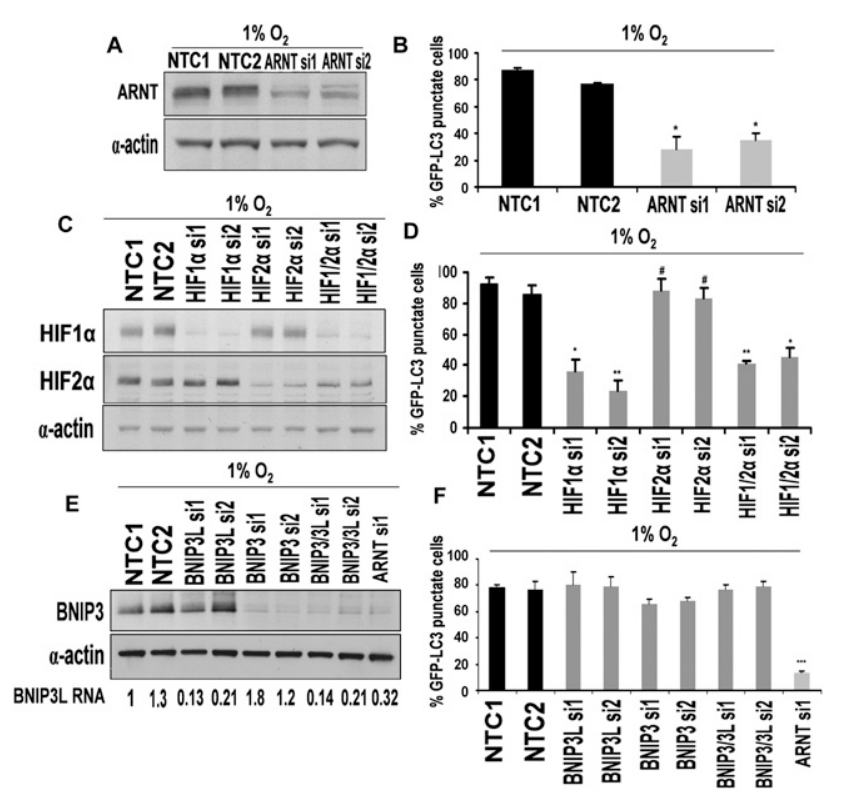

Figure 3. Hypoxia-induced autophagy in tumor cells is mediated via HIF1 $\alpha /$ ARNT. $(A, B)$ BE GFP-LC3 cells were transfected with indicated siRNA oligonucleotides (nontargeting controls [NTCs] or ARNT targeting), and at $48 \mathrm{~h}$ post-transfection were cultured in SFM overnight and then exposed to hypoxia for $8 \mathrm{~h}$ before immunoblot analysis $(A)$ or scoring of the number of GFP-LC3 puncta-positive cells $(B)\left(n=3 \pm\right.$ SEM; $\left.^{*}{ }^{\star}\right] P<0.05$ vs. each NTC). $(C, D)$ BE GPP-LC3 cells were transfected with indicated siRNA oligonucleotides (nontargeting controls [NTCs] or HIF $1 \alpha$ or HIF $2 \alpha$ targeting; HIF $1 / 2 \alpha$ sil is equimolar mix of HIF1 $\alpha$ si 2 and HIF $2 \alpha$ sil and HIF $1 / 2 \alpha$ si 2 is equimolar mix of HIF $1 \alpha$ sil and $H I F 2 \alpha$ si2), and at $24 \mathrm{~h}$ posttransfection were cultured in SFM overnight and exposed to hypoxia for $8 \mathrm{~h}$. Immunoblot analysis $(C)$ or scoring of the number of GFPLC3 puncta-positive cells $(D)\left(n=3 \pm \mathrm{SEM}\left[{ }^{\star}\right] P<0.05\right.$ vs. each NTC; $\left[{ }^{\star \star}\right] P<0.01 ;[\#]$ not significant). $(E, F)$ BE GFP-LC3 cells were transfected with indicated siRNA oligonucleotides (nontargeting controls [NTCs], BNIP3 targeting, BNIP3L targeting, or ARNT targeting positive controls; BNIP3/3L sil is equimolar mix of BNIP3 sil and BNIP3L si2 and BNIP3/3L si2 is equimolar mix of BNIP3 si2 and BNIP3L sil), and at $48 \mathrm{~h}$ post-transfection were cultured in SFM overnight and then exposed to hypoxia for $8 \mathrm{~h}$ before immunoblot analysis $(E$, top $)$ and quantitation of relative BNIP3L mRNA levels by real-time PCR (E, bottom) or scoring of the number of GFP-LC3 puncta-positive cells $(F)\left(n=3 \pm \mathrm{SEM}_{;}\left[{ }^{\star}\right] P<0.05\right.$ vs. each NTC; $\left[{ }^{\star \star}\right] P<0.01 ;[\#]$ not significant $)$.

of BNIP3 and BNIP3L function, consistent with the lack of a mitophagic component to this autophagy.

We next wished to determine the point at which PDGFR signaling converged with hypoxia signaling to mediate macroautophagy. Gene expression profiling revealed that PDGFR family inhibition affects HIF1 $\alpha$ activity, as read out in the transcriptional response to hypoxia (Fig. 4A). Microarray analysis defined 281 signals up-regulated by hypoxia. These signals were then compared against those from hypoxic cells with either $H I F 1 \alpha$ silencing or PDGFR-I treatment. On this basis, genes were assigned as less up-regulated by hypoxia under these inhibitory treatment conditions (Fig. 4A, green), further up-regulated, or unaffected (Fig. 4A, red or black, respectively; complete listing in Supplemental Fig. 4; Supplemental Table 1). Most genes required HIF1 $\alpha$ for up-regulation, but only a proportion of these HIFl $\alpha$ targets also required PDGFR family activity. Thus, HIF $1 \alpha$ target genes are divisible into two groups: a set requiring 


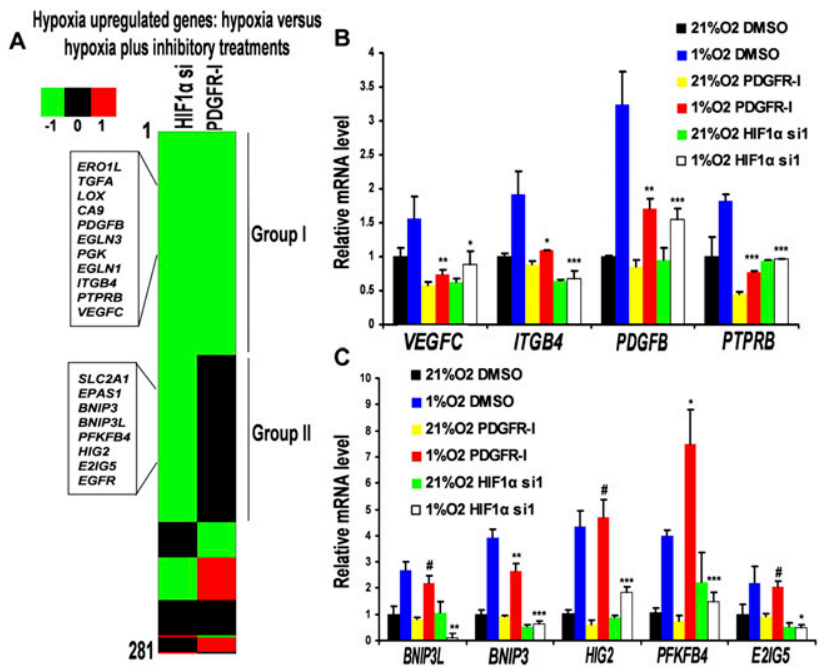

Figure 4. PDGFR family signaling facilitates a subset of HIF $1 \alpha$ transcriptional responses. (A) Microarray analysis of BE GFP-LC3 cells exposed to hypoxia with or without inhibitory treatments targeting PDGFR family kinase activity (PDGFR-I) or HIF $1 \alpha$ protein levels (HIFl $\alpha$ si). Cells were transfected with NTC1 or HIF $1 \alpha$ si 2 and then switched to SFM overnight at $48 \mathrm{~h}$ post transfection. Subsequent treatments were $8 \mathrm{~h}$ with DMSO (onto NTC1 or HIFl $\alpha$ siRNA transfected cells) or PDGFR-I ( $5 \mu \mathrm{M}$ ) (onto NTC1 transfected cells) under either normoxia $\left(21 \% \mathrm{O}_{2}\right)$ or hypoxia $\left(1 \% \mathrm{O}_{2}\right)$. RNA was then subjected to microarray analysis. Two-hundred-eighty-one gene signals defined as being up-regulated in hypoxic vehicle condition relative to normoxia vehicle condition were analyzed for differences between hypoxia vehicle condition and hypoxia with additional inhibitory treatments (PDFGR-I treatment or HIF1 $\alpha$ RNAi). Green signals indicate genes less up-regulated by hypoxia when inhibitory treatment is applied. Red signals indicate genes more up-regulated, and black indicates those with no significant difference. Group I consists of genes whose hypoxic increase in expression is reduced by PDGFR-I treatment or HIF1 $\alpha$ siRNA. Group II consists of genes whose hypoxic increase in expression is sensitive to HIF $1 \alpha$ siRNA but not PDGFR-I treatment. Examples of genes in each group are given in boxes alongside (for a comprehensive list, see Supplemental Fig. 4; Supplemental Table 1). (B) RNA used for microarray analysis in $A$, which was subjected to real-time PCR quantification of four Group I genes $(n=3 \pm S D)$. $(C)$ RNA used for microarray analysis in $A$, which was subjected to real-time PCR quantification of five Group II genes $\left.\left.(n=3 \pm \mathrm{SD}) .\left.(B, C)\right|^{*}\right) P<0.05 ;{ }^{*}\right) P<0.01_{i}\left(^{\star \star \star}\right) P<$ 0.005 ; (\#)not significant, vs. hypoxia alone.

PDGFR family activity for up-regulation and within which are those driving hypoxia-induced macroautophagy (Group I, Fig. 4A), and a set not requiring PDGFR family activity for up-regulation (Group II, Fig. 4A). Quantitative RT-PCR (qRT-PCR) analysis of the transcript levels of genes from the microarray analysis confirmed this pattern of regulation (Fig. 4B,C). Genes such as VEGFC, ITGB4, PDGFB, and PTPRB were upregulated by hypoxia, and up-regulation was abrogated by HIF1 $\alpha$ siRNA or PDGFR-I inhibitor (Fig. 4B). Genes such as BNIP3L, BNIP3, HIG2, PFKFB4, and E2IG5 were up-regulated by hypoxia, and up-regulation was abrogated by HIF1 $\alpha$ siRNA and only partially or insignificantly affected by PDGFR-I treatment (Fig. 4C). Similar data were obtained with PDGFR-II (Supplemental Fig. 5). These data demonstrate that PDGFR signaling broadens the HIF $1 \alpha$ transcriptome and increases the scope of the adaptive response to hypoxia. This broadened transcriptional response has the capacity to promote macroautophagy.
As the data indicated that autocrine PDGFR signaling affects HIF $1 \alpha$ function at some target promoters, we now wished to determine the mechanism of this inhibition. First, minimal hypoxia response element (HRE) reporter assays using a sensitive HIF-binding site from phosphoglycerate kinase (PGK), a Group I gene, revealed a decrease in hypoxic HIF-binding activity in the absence of PDGFR signaling (Fig. 5A). This indicated that the activity of the HIFl $\alpha$ transcriptional complex itself, involved in activating the core elements of target promoters, was perturbed. We decided to examine HIF $1 \alpha$ behavior more closely. At steady-state, post-hypoxic induction of macroautophagy, we found an approximately equal amount of HIFl $\alpha$ present in control cells and cells treated with PDGFR inhibitor, and HIF1 $\alpha$ was localized to the nuclear compartment-to which shuttling is

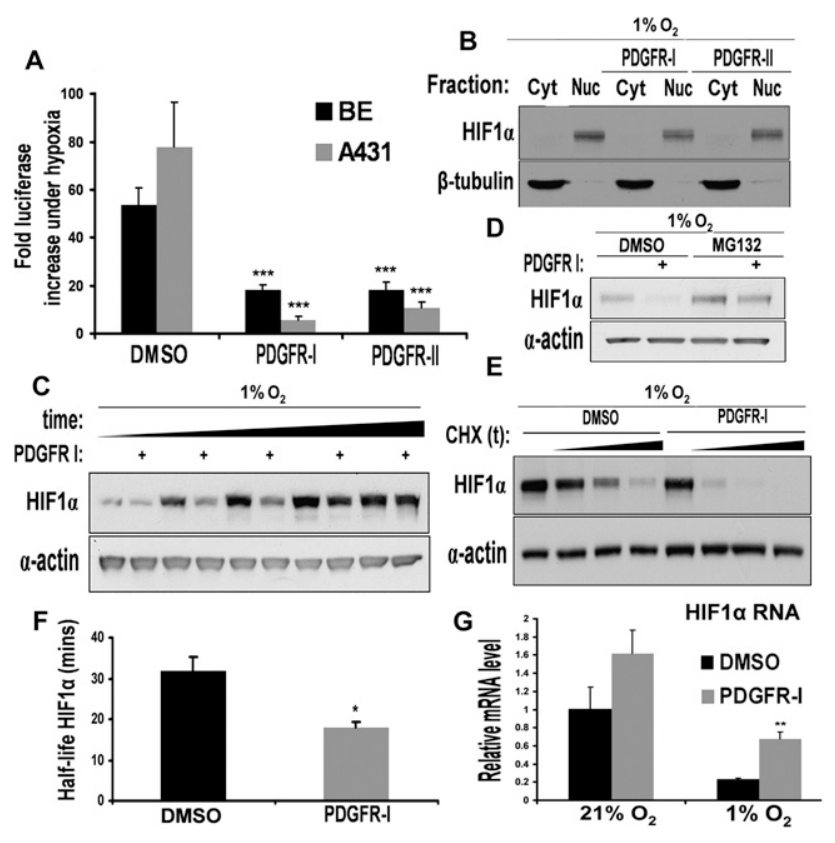

Figure 5. PDGFR family signaling regulates the kinetics of HIF $1 \alpha$ protein turnover. (A) BE GFP-LC3 and A431 GFP-LC3 cells were assayed for HIF-dependent transcription by transfection of wild-type PGK HRE (wHRE) and mutant HRE reporter (mHRE) constructs as described in the Materials and Methods, and then overnight culture in SFM with DMSO vehicle or PDGFR-I $(5 \mu \mathrm{M})$ followed by luciferase assay. Graph shows fold increase in wHRE/mHRE signal in hypoxic cultures $\left(n=3 \pm \mathrm{SD}\left[^{\star \star \star}\right] P<0.005\right.$ vs. DMSO). (B) Confluent BE GFP-LC3 cells were cultured in SFM under hypoxic conditions for $8 \mathrm{~h}$ with DMSO, PDGFR-I $(5 \mu \mathrm{M})$, or PDGFR-II (20 $\mu \mathrm{M})$; fractionated into cytosolic (Cyt) or nuclear (Nuc) fractions; and probed for indicated proteins. Confluent BE GFP-LC3 cells were cultured in SFM under hypoxic conditions for $8 \mathrm{~h}$, with DMSO or PDGFR-I $(5 \mu \mathrm{M})(C, D)$ and in the presence or absence of MG132 (20 $\mu \mathrm{M})(D)$. Cells were lysed at $1 \mathrm{~h}, 2 \mathrm{~h}, 3 \mathrm{~h}, 4 \mathrm{~h}$, and $6 \mathrm{~h}(C)$ or $2 \mathrm{~h}(D)$ and probed for indicated proteins. (E) Confluent BE GFP-LC3 cells were cultured in SFM under hypoxic conditions for $8 \mathrm{~h}$ with DMSO or PDGFR-I $(5 \mu \mathrm{M})$. Then $(t=0)$, a sample was lysed and cycloheximide (100 $\left.\mu \mathrm{g} \cdot \mathrm{mL}^{-1}\right)$ was added to cultures, with lysis of cells performed every subsequent $20 \mathrm{~min}$. Lysates were immunoblotted for $\mathrm{HIF} 1 \alpha$ as shown in representative figure $(E)$, and half-lives of HIF $1 \alpha$ protein were calculated after quantification $(F)\left(n=3 \pm \mathrm{SEM}_{\text {; }}\right.$ $\left.\left[{ }^{\star}\right] P<0.05\right) .(G)$ Confluent BE GFP-LC3 cells were cultured in SFM under normoxic or hypoxic conditions for $8 \mathrm{~h}$ with DMSO or PDGFR-I $(5 \mu \mathrm{M})$, and RNA was extracted and subjected to real-time PCR quantification of HIFl $1 \alpha$ mRNA $\left(n=3 \pm \mathrm{SD} ;{ }^{\star \star}{ }^{\star}\right] P<0.01$ vs. DMSO). 
required to effect transactivation-in both instances (Fig. 5B). However, a time course of the events immediately following exposure of cells to hypoxia demonstrated that cells with inhibited PDGFR signaling exhibit a retarded accumulation of $\mathrm{HIF} 1 \alpha$ protein only at early time points (Fig. 5C) due to enhanced proteasomal degradation, as shown by treatment with MG-132 proteasome inhibitor (Fig. 5D). However, even after several hours, when steadystate levels of HIF1 $\alpha$ protein in cells lacking PDGFR signaling have recovered to those seen in uncompromised cells, the degradation rate of $\mathrm{HIF} 1 \alpha$ is still markedly enhanced, as demonstrated by cycloheximide chase experiments (Fig. 5E,F). However, the steady-state levels of $\mathrm{HIF} 1 \alpha$ are buffered by a compensatory increase in HIF1 $\alpha$ mRNA in the absence of PDGFR signaling, due to the abrogation of a negative feedback loop that operates to repress HIF1 $\alpha$ mRNA under control hypoxic conditions (Fig. 5G). Taken together, these data suggest that a more dynamic and transient pool of HIF $1 \alpha$ protein in the absence of PDGFR signaling, being turned over faster due to balanced increases in both synthesis and degradation, has less capacity to promote transcription from HRE-containing target genes (for model, see Supplemental Fig. 6).

Macroautophagy is regulated downstream from diverse stress signals through different signaling pathways. Here we demonstrated PDGFR-mediated regulation of a hypoxia HIFl $\alpha$-driven mechanism for induction of macroautophagy. It is worth noting, however, that in extreme situations, such as anoxia $\left(<0.01 \% \mathrm{O}_{2}\right)$, HIF-independent, and presumably PDGFR-independent, mechanisms have been suggested to play a dominant role in regulating macroautophagy (Papandreou et al. 2008). Interestingly, it has been shown previously that IL-3 promotes nutrient uptake, presumably by binding to its cognate growth factor receptor, and deprivation of this signal causes a starvation response and induction of autophagic survival (Lum et al. 2005). Here we described a different paradigm for growth factor receptor signaling in the regulation of macroautophagy, where signaling facilitates the maximum cellular response to a cellular stress, in this instance hypoxia. We propose that autocrine PDGFR signaling allows tumor cells to autonomously maintain a level of HIF $1 \alpha$ activity at a given oxygen tension and HIF $1 \alpha$ protein level that is greater than it would be without this signaling. This is attained by increasing the half-life of HIF1 $\alpha$, which is prevented from causing runaway accumulation of HIFl $\alpha$ protein by negative feedback on HIFl $\alpha$ message levels. The consequence of the presence of this less dynamic and transient pool of HIF1 $\alpha$ protein is to increase the number of phenotypic changes promoted by HIFl $\alpha$ at a given oxygen tension, and thus the number of strategies available to the tumor cell to adapt to low oxygen and the consequent metabolic stress. One such change is the induction of macroautophagy involving cytosolic protein and p62 degradation under hypoxia, distinct from the mitophagy seen in MEFs that acts to down-regulate oxidative phosphorylation (Zhang et al. 2008). Macroautophagy maintains cell viability in the face of metabolic stress. The autocrine signaling of PDGFR thus gives an obvious advantage to tumor cells by enabling survival in a hypoxic microenvironment during tumorigenesis.

In conclusion, identifying signaling mechanisms by which tumor cells promote macroautophagic responses to metabolic stresses, such as PDGFR signaling in response to hypoxia, will provide new targets for selective therapeutic targeting of tumor cell viability.

\section{Materials and methods}

\section{Cell lines and reagents}

BE, A431, and HCT116 cells expressing ecotropic retrovirus receptor (a gift from Dan Croft) stably infected with pBabe-Puro EGFP-LC3 retrovirus ("GFP-LC3" lines), and primary MEF cells were cultured in DMEM (Gibco) supplemented with 10\% FBS (Hyclone). Drosophila melanogaster S2R ${ }^{+}$GFP-LC3 cells were derived from S2R ${ }^{+}$cells stably transfected with pAc5.1 (Invitrogen) engineered to express EGFP-Drosophila Atg8a and cultured at room temperature and atmospheric oxygen in Schneider's Drosophila medium. All mammalian cell lines were cultured in $21 \% \mathrm{O}_{2} /$ $5 \% \mathrm{CO}_{2}$ or, in the case of diminished $\mathrm{O}_{2}$, in an InVivo 500 hypoxia workstation at $5 \% \mathrm{CO}_{2}$. MG132, E64d, pepstatin A, PDGFR-I (alias PDGF Receptor Tyrosine Kinase Inhibitor III), and PDGFR-II (alias PDGF Receptor Tyrosine Kinase Inhibitor I) inhibitors were obtained from Calbiochem. Bafilomycin and cycloheximide were from Sigma. Recombinant PDGF-AB was from R\&D Systems, and recombinant FMS was from Cell Signaling Technology (CSF1R [K539-C972]). ELISAs were performed with Quantikine immunoassay kits for human PDGF-AB and M-CSF from R\&D Systems

\section{Microscopy}

GFP-LC3 cells were grown on glass and fixed in $4 \%$ paraformaldehyde before mounting using DAKO mountant (DAKO Cytomation). Confocal images were obtained as Z-stacks using a Leica SP2 confocal. Cells were scored blindly for presence of GFP-LC3 puncta in multiple epifluorescence images ( $>10$ per condition, $>200$ cells) obtained using a $100 \times$ objective lens on an Axioskop 50 microscope (Zeiss). Automatic exposure times minimized differences in brightness between images due to heterogeneous expression among cells.

\section{Acknowledgments}

Thanks to Greg Findlay and Richard Lamb for generous gifts of reagents. Thanks to Yvonne Hey for microarray handling, and Keith Vass for microarray data analysis. Thanks to Dan Croft, Gareth Inman, and Dan Tennant for advice and comments. Work in the Tumour Cell Death Laboratory is supported by Cancer Research UK.

\section{References}

Boya P, Gonzalez-Polo RA, Casares N, Perfettini JL, Dessen P, Larochette N, Metivier D, Meley D, Souquere S, Yoshimori T, et al. 2005. Inhibition of macroautophagy triggers apoptosis. Mol Cell Biol 25: 1025-1040.

Colell A, Ricci JE, Tait S, Milasta S, Maurer U, Bouchier-Hayes L, Fitzgerald P, Guio-Carrion A, Waterhouse NJ, Li CW, et al. 2007. GAPDH and autophagy preserve survival after apoptotic cytochrome c release in the absence of caspase activation. Cell 129: 983-997.

Crighton D, Wilkinson S, O'Prey J, Syed N, Smith P, Harrison PR, Gasco M, Garrone O, Crook T, Ryan KM. 2006. DRAM, a p53-induced modulator of autophagy, is critical for apoptosis. Cell 126: 121-134.

Degenhardt K, Mathew R, Beaudoin B, Bray K, Anderson D, Chen G, Mukherjee C, Shi Y, Gelinas C, Fan Y, et al. 2006. Autophagy promotes tumor cell survival and restricts necrosis, inflammation, and tumorigenesis. Cancer Cell 10: 51-64.

Feng Z, Zhang H, Levine AJ, Jin S. 2005. The coordinate regulation of the p53 and mTOR pathways in cells. Proc Natl Acad Sci 102: 82048209.

Hara T, Nakamura K, Matsui M, Yamamoto A, Nakahara Y, SuzukiMigishima R, Yokoyama M, Mishima K, Saito I, Okano H, et al. 2006. Suppression of basal autophagy in neural cells causes neurodegenerative disease in mice. Nature 441: 885-889.

Jin S, Dipaola RS, Mathew R, White E. 2007. Metabolic catastrophe as a means to cancer cell death. J Cell Sci 120: 379-383. 


\section{Wilkinson et al.}

Kabeya Y, Mizushima N, Ueno T, Yamamoto A, Kirisako T, Noda T, Kominami E, Ohsumi Y, Yoshimori T. 2000. LC3, a mammalian homologue of yeast Apg8p, is localized in autophagosome membranes after processing. EMBO J 19: 5720-5728.

Komatsu M, Waguri S, Chiba T, Murata S, Iwata II, Tanida I, Ueno T, Koike M, Uchiyama Y, Kominami E, et al. 2006. Loss of autophagy in the central nervous system causes neurodegeneration in mice. Nature 441: 880-884.

Kuma A, Hatano M, Matsui M, Yamamoto A, Nakaya H, Yoshimori $T$, Ohsumi Y, Tokuhisa T, Mizushima N. 2004. The role of autophagy during the early neonatal starvation period. Nature 432: 1032-1036.

Lum IJ, Bauer DE, Kong M, Harris MH, Li C, Lindsten T, Thompson CB. 2005. Growth factor regulation of autophagy and cell survival in the absence of apoptosis. Cell 120: 237-248.

Mizushima N, Yamamoto A, Matsui M, Yoshimori T, Ohsumi Y. 2004. In vivo analysis of autophagy in response to nutrient starvation using transgenic mice expressing a fluorescent autophagosome marker. Mol Biol Cell 15: 1101-1111.

Papandreou I, Lim AL, Laderoute K, Denko NC. 2008. Hypoxia signals autophagy in tumor cells via AMPK activity, independent of HIF-1, BNIP3, and BNIP3L. Cell Death Differ 15: 1572-1581.

Pouyssegur J, Dayan F, Mazure NM. 2006. Hypoxia signalling in cancer and approaches to enforce tumour regression. Nature 441: 437-443.

Sandoval H, Thiagarajan P, Dasgupta SK, Schumacher A, Prchal JT, Chen M, Wang J. 2008. Essential role for Nix in autophagic maturation of erythroid cells. Nature 454: 232-235.

Scott RC, Schuldiner O, Neufeld TP. 2004. Role and regulation of starvation-induced autophagy in the Drosophila fat body. Dev Cell 7: 167-178.

Shimizu S, Kanaseki T, Mizushima N, Mizuta T, Arakawa-Kobayashi S, Thompson CB, Tsujimoto Y. 2004. Role of Bcl-2 family proteins in a non-apoptotic programmed cell death dependent on autophagy genes. Nat Cell Biol 6: 1221-1228.

Tracy K, Dibling BC, Spike BT, Knabb JR, Schumacker P, Macleod KF 2007. BNIP3 is an RB/E2F target gene required for hypoxia-induced autophagy. Mol Cell Biol 27: 6229-6242.

Xie Z, Klionsky DJ. 2007. Autophagosome formation: Core machinery and adaptations. Nat Cell Biol 9: 1102-1109.

Xue L, Fletcher GC, Tolkovsky AM. 2001. Mitochondria are selectively eliminated from eukaryotic cells after blockade of caspases during apoptosis. Curr Biol 11: 361-365.

Yu L, Alva A, Su H, Dutt P, Freundt E, Welsh S, Baehrecke EH, Lenardo MJ. 2004. Regulation of an ATG7-beclin 1 program of autophagic cell death by caspase-8. Science 304: 1500-1502.

Zhang H, Bosch-Marce M, Shimoda LA, Tan YS, Baek JH, Wesley JB, Gonzalez FJ, Semenza GL. 2008. Mitochondrial autophagy is an HIF1-dependent adaptive metabolic response to hypoxia. I Biol Chem 283: 10892-10903. 


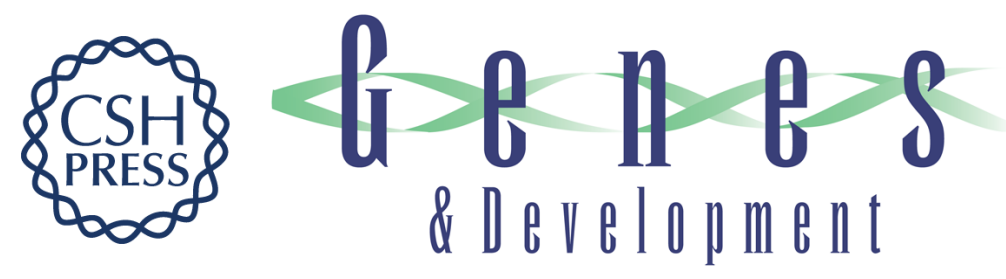

\section{Hypoxia-selective macroautophagy and cell survival signaled by autocrine PDGFR activity}

Simon Wilkinson, Jim O'Prey, Michael Fricker, et al.

Genes Dev. 2009, 23:

Access the most recent version at doi:10.1101/gad.521709

Supplemental http://genesdev.cshlp.org/content/suppl/2009/05/20/23.11.1283.DC1
Material

References This article cites 22 articles, 8 of which can be accessed free at:

http://genesdev.cshlp.org/content/23/11/1283.full.html\#ref-list-1

License

Email Alerting

Service

Receive free email alerts when new articles cite this article - sign up in the box at the top right corner of the article or click here.

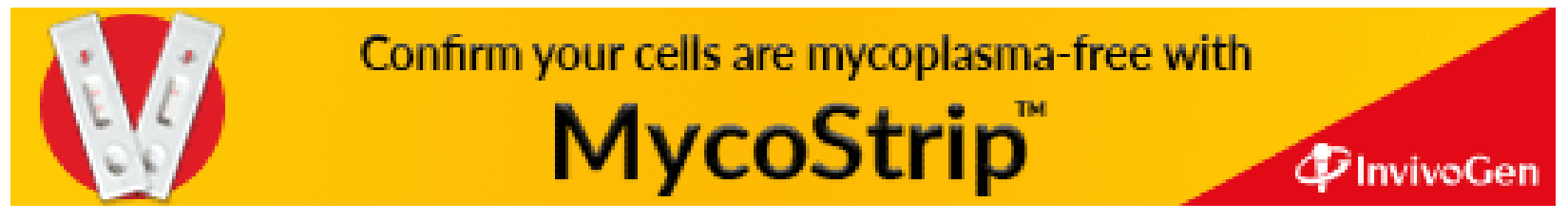

